\title{
KNOWLEDGE TRANSFER: CURRENT STATE AND PROBLEMS
}

\section{Nataliya Hapak ${ }^{1}$ \\ Yaroslav Bojko ${ }^{2}$}

DOI: https://doi.org/10.30525/978-9934-26-050-6-33

As part of the study «Improving the efficiency of the knowledge triangle in the region», conducted by the Transcarpathian Regional Center for SocioEconomic and Humanitarian Studies of the National Academy of Sciences of Ukraine, a survey of research institutions and universities in the Transcarpathian region of Ukraine. The main purpose of their survey is to identify the state and problems in the field of knowledge transfer in the region. At the same time, the following trends were identified.

\footnotetext{
${ }^{1}$ Uzhhorod National University, Ukraine

${ }^{2}$ Uzhhorod National University, Ukraine
} 
$75 \%$ of the surveyed scientific and research institutions of the Transcarpathian region perform research at the request of the state (in the format of state research). The main benefits of knowledge transfer for organizations that disseminate knowledge, respondents see in receiving funds from the implementation, improving the material and technical base, expanding sources of funding for the research fund, financial investments. That is, these benefits are mainly related to additional financial income.

When assessing the risks of knowledge transfer (for a knowledge-sharing organization), half of the surveyed research institutions indicated misuse of technology and loss of reputation. For those companies that receive knowledge, such risks are absent (according to $75 \%$ of respondents). On the positive side, $75 \%$ of surveyed research institutions have stated their intention to continue the practice of knowledge transfer in the future, but under the conditions of the state approach to solving the problems of cooperation. Also, all surveyed institutions recognized the importance of knowledge transfer. Highlighting the key success factors, the respondents pointed out the importance of the communicative factor (interaction of universities and business structures), scientific support and the current level of material and technical base.

$75 \%$ of respondents say that neither government nor regional funding has become a driving force for knowledge transfer. At the same time, half of the surveyed research institutions note the extreme difficulty of obtaining funding. 25\% of respondents emphasize the importance of public funding. Similarly, $75 \%$ of surveyed research institutions reported a practical lack of benefit from any policy measures / initiatives at EU, national or regional level. $25 \%$ said that there are cooperation agreements with four countries, but they do not provide funding and do not contribute to its expansion.

The findings show that all respondents have problems with the financial support of their research activities. There are almost no regional investments for co-financing. State funding received by respondents (95-100\% of funds) is insufficient. It has not become a driving factor in the transfer of knowledge. Thus, the sources of funding for research in the region are dominated by state budget funds, which mainly go to finance current needs. This, in turn, slows down the scale of such activities and does not ensure their proper deployment.

Also, all scientific and research institutions try to take an active part in the transfer of knowledge, holding seminars, conferences, round tables, etc. This promotes joint activities between research institutions / universities, increases professional competence, there are opportunities for practical use of research results. But $75 \%$ of respondents said that the main obstacle is the lack of adequate financial security. 25\% of respondents consider the lack of links between innovation developers and production to be a significant obstacle. 
Most respondents believe that the impact of research institutions / universities on the economic and social well-being of a city or region is expressed in improving the quality of human capital, objective assessment of economic potential and analysis of the potential of the region. $25 \%$ of respondents noted that this impact is due to the implementation of their recommendations in the work of small businesses and other institutions of the city / region.

The revealed results indicate that at the regional level the role of research institutions and higher education institutions in the development of innovations and knowledge transfer is very small. The main reason for this is underfunding, which leads to the inability to keep up with the times and thus the lack of interest of manufacturing companies to seek help in innovation. Research carried out in the Transcarpathian region of Ukraine and further developed is mainly carried out through personal connections of scientific and technical staff with partners from abroad. 